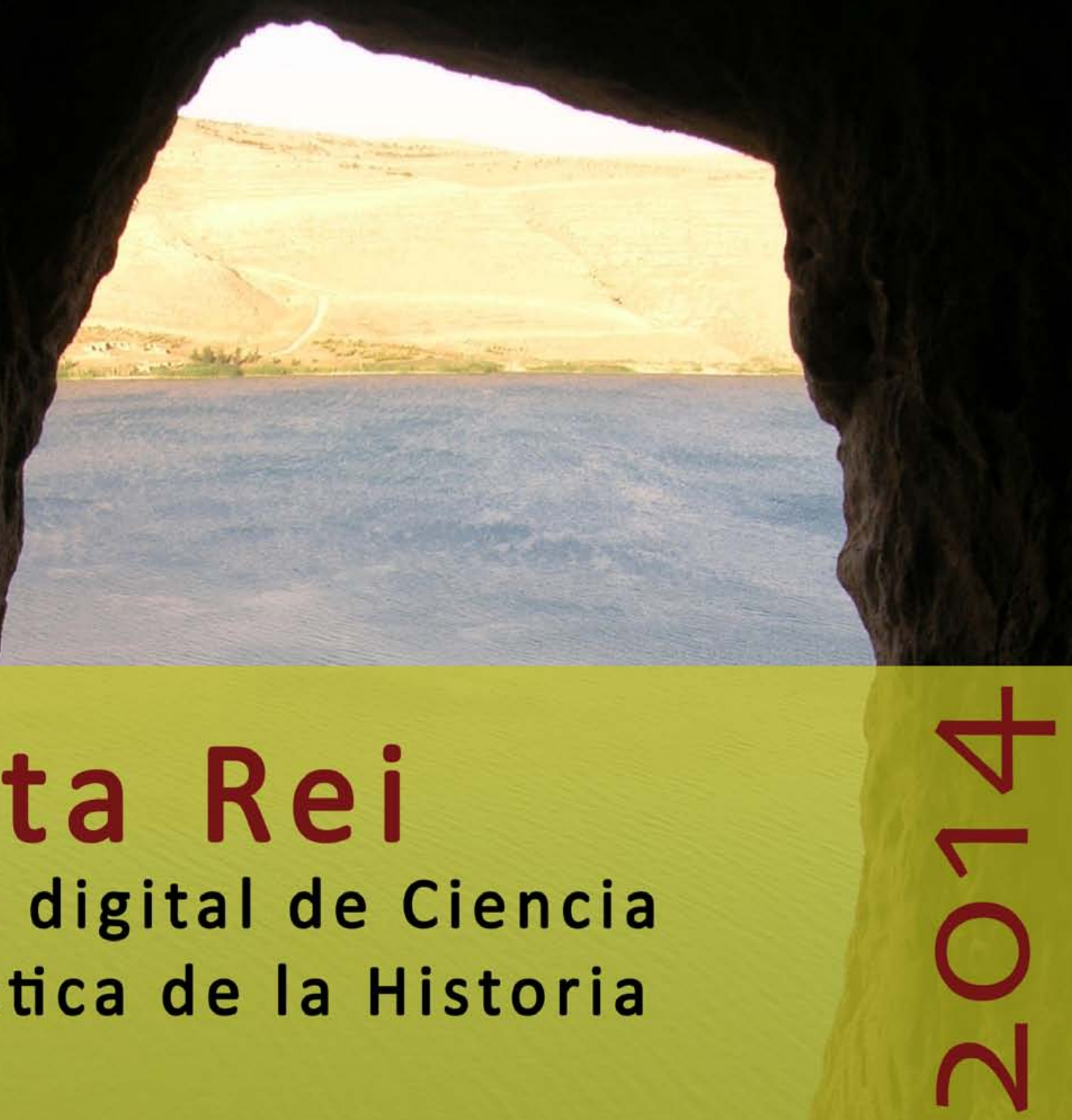





\section{Panta

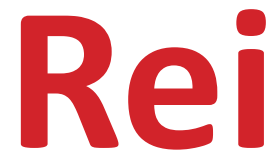 \\ Revista Digital de Ciencia \\ y Didáctica de la Historia}

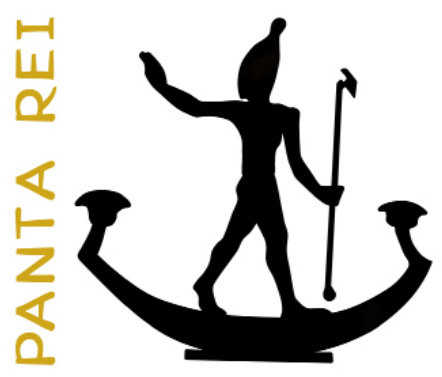

2014

Revista anual

Fecha de inicio: 1995

Revista Panta Rei. pantarei@um.es

\section{Edita:}

Centro de Estudios del Próximo Oriente y la

Antigüedad Tardía - CEPOAT

Edificio Universitario Saavedra Fajardo.

Universidad de Murcia

C/ Actor Isidoro Máiquez, 9

30007 - MURCIA - ESPAÑA

Teléfono: (+34) 868883890

cepoat@um.es

Web: www.um.es/cepoat/pantarei

Edición 2014

ISSNe: 2386-8864

ISSN: $1136-2464$

Depósito legal: MU-966-1995
cepoAt

UNIVERSIDAD DE MURCIA centro de estudios del próximo oriente y la antigüedad tardia

En Portada: Río Éufrates desde un eremitorio cristiano primitivo (Fotografía de Alejandro Egea).

Responsables de los textos:

Sus autores.

Responsable de la presente edición: Consejo Editorial Panta Rei. 


\section{CONSEJO DE REDACCIÓN}

\section{Coordinador editorial}

Egea Vivancos, Alejandro

[Didáctica de las Ciencias Sociales, UMU]

\section{Editores}

Botí Hernández, Juan Jesús

[CEPOAT, UMU]

Sáez Giménez, David Omar [CEPOAT, UMU]

\section{Secretaria}

Arias Ferrer, Laura

[Didáctica de las Ciencias Sociales, UMU]

\section{Responsable informático}

Martínez García, José Javier

[CEPOAT, UMU]

\section{Traducción y corrección lingüística}

Martínez Martínez, Cristina

[Sociedad Española de Lenguas Modernas]

\section{CONSEJO ASESOR}

Albero Muñoz, M. ${ }^{a}$ del Mar [H. ${ }^{a}$ del Arte, UMU]

Cobacho López, Ángel

[Derecho, UMU]

Egea Bruno, Pedro M. ${ }^{a}$

[Historia Contemporánea, UMU]

García Atienzar, Gabriel

[Prehistoria, UA]

González Monfort, Neus

[Didáctica de las Ciencias Sociales, UAB]

Haber Uriarte, María

[Prehistoria, UMU]

Irigoyen López, Antonio

[Historia Moderna, UMU]

Mahony, Simon

[Digital Humanities, UCL, Reino Unido]

Marsilla de Pascual, Francisco Reyes

[Técnicas historiográficas, UMU]

Miralles Maldonado, José Carlos

[Filología Clásica, UMU]

Molina Gómez, José Antonio

[Historia Antigua, UMU]

Noguera Celdrán, José Miguel

[Arqueología, UMU]

Pérez Molina, Miguel Emilio

[Filología Clásica, UMU]

Prados Martínez, Fernando

[Arqueología, UA]

Sánchez Ibáñez, Raquel

[Didáctica de las Ciencias Sociales, UMU]

Sancho Gómez, Miguel Pablo

[Educación, UCAM]

Vilar García, María José

[Historia Contemporánea, UMU] 
Presentación

Todo fluye. Renovarse y crecer

Alejandro Egea Vivancos, Laura Arias Ferrer, Juan Jesús Botí Hernández y David Omar Sáez Giménez

Artículos

La sociedad hiperbórea: ¿utopía o mito? Reflexiones acerca de la naturaleza y significado del relato hiperbóreo.

José Ángel Castillo Lozano.

Aproximación a la figura de una matrona romana culta y poderosa. El caso de Julia Domna.

Consuelo Isabel Caravaca Guerrero.

¡Arrasar la Vendée! Guerra Civil y Columnas Infernales en pleno corazón de la Revolución Francesa.

Benjamín Cutillas Victoria.....

Arte y expresión en el pensamiento de E. H. Gombrich.

Patricia Castiñeyra Fernández.

Odiseo a través de la parodia. Desmitificación e ironía de una Ítaca nostálgica en Prometeo de Pérez de Ayala y ¿Por qué corres, Ulises? de Gala.

Carmen María López López.

Análisis de la actividad didáctica del Museo de Arte Ibérico El Cigarralejo (Mula, Murcia).

Julio García Toral......

La Transición española en $4 .^{\circ}$ ESO. Un estudio de caso de los significados.

Borja Santiago Arnoso.

Entrevista

Entrevista al profesor D. Michael Walker.

Consuelo Isabel Caravaca Guerrero.

Reseñas

II Congreso de la Asociación Internacional de Investigación para la Educación de la Historia y las Ciencias Sociales.

Elvira Barriga y Rodrigo Salazar.

I Congreso de Jóvenes Investigadores del Mundo Antiguo de la Universidad de Murcia.

Pedro David Conesa Navarro

II Congreso Internacional de Educación Patrimonial.

Tània Martínez Gil.....

Ruiz-Gálvez Pliego, M. (2013). Con el fenicio en los talones. Los inicios de la Edad del Hierro en la cuenca del Mediterráneo. Barcelona: Editorial Bellaterra. 377 págs.

Celso Sánchez Mondéjar..

Normas de publicación/Publishing rules 



\title{
Arte y expresión en el pensamiento de E. H. Gombrich
}

\author{
Art and expression in Gombrich's thought
}

\author{
Patricia Castiñeyra Fernández \\ Universidad de Murcia
}

Recibido: 29/05/2014

Aceptado: 30/07/2014

Para citar este artículo: Castiñeyra Fernández, P. (2014). Arte y expresión en el pensamiento de E. H. Gombrich. Panta Rei. Revista Digital de Ciencia y Didáctica de la Historia, 59-70.

ISSNe: $2386-8864$

DOI: http://dx.doi.org/10.6018/pantarei/2014/5

\section{Resumen}

El siguiente trabajo hace un recorrido a través de las principales ideas que el gran historiador del arte, E. H. Gombrich, ha creado sobre la teoría de la expresión artística. Teniendo siempre en cuenta la formación e influencias de este autor, entre las que se encuentran la Escuela de Viena, Karl Popper o Ernst Kris, reuniremos las ideas que encontramos dispersas entre sus diversas obras y artículos que tienen que ver con la representación de las emociones o la percepción de la expresión. Su teoría estará basada en las "Cuatro Teorías de la Expresión Artística", especialmente en la cuarta, que está ideada por él mismo y es un punto intermedio entre las anteriores, donde el artista se convierte en el protagonista.

\section{Palabras clave}

Teoría, percepción, artista, espectador, emoción.

\begin{abstract}
The following work looks through the main ideas that the great art historian, Ernst $\mathrm{H}$. Gombrich created about the theory of artistic expression. Having always in mind his formation and influences, as the School of Vienna, Karl Popper and Ernst Kris, we will gather the ideas scattered among several of his books and articles in relation to the representation of emotions or the reception of the expression. His theory is based on the so-called "Four Theories of Artistic Expression", particularly in the fourth one, which had been created by himself and that is a middle point between the three previous ones, where the artist becomes the main character of the art and the artistic expression.
\end{abstract}

\section{Key words}

Theory, perception, artist, spectator, emotion. 


\section{Introducción}

El arte está formado de innumerables intenciones, ideas, sensibilidades, estéticas, etc., que hacen que una obra cobre su propio sentido, según el autor que la realice, la época y, en resumen, el contexto en que se dé. Es mediante la teoría del arte como podemos llegar a comprender todos esos aspectos que nos ayudan a llegar hasta el significado último de la obra; como diría Danto (1964), ese "mundo del arte" que hace, no sólo que comprendamos la obra, sino que la propia obra se constituya como tal. Uno de los historiadores y teóricos del arte más importantes y prolíficos es E.H. Gombrich, en quien se basa este trabajo.

Dentro del pensamiento de Gombrich sobre el arte encontramos muchos campos a los que dedica estudios amplios, pero este trabajo se centra en los que dedica al arte y la expresión, reuniendo sus ideas principales. Gombrich estudiará este tema siempre partiendo de su concepción multidisciplinar de la Historia del Arte, por lo que veremos cómo tiene en cuenta todos los aspectos posibles: convenciones o tradiciones culturales, la recepción del espectador, la idea del artista... e incluso el psicoanálisis, así como la coyuntura histórica, el gusto del momento o la situación económica. Pese a que la expresión en el arte es uno de los estudios más importantes e interesantes de este historiador, no es uno de sus temas más difundidos o analizados. Es por esto que hemos decidido intentar reunir algunos de los conceptos que podemos dilucidar sobre la expresión dentro de los escritos de Gombrich.

Como Woodfield nos dice en la introducción del libro Gombrich Esencial, "no es descabellado pensar que el nombre de Gombrich resulta más familiar a una gran cantidad de personas que el de cualquier otro historiador del arte" (1996, p. 9), y es que sus obras han sido ampliamente difundidas, gracias al estilo distendido del autor, que hace posible una fácil lectura y comprensión de sus obras. Podemos, por tanto, entender la gran figura que Gombrich representa para la Historia del Arte.

Ernst Hans Josef Gombrich nació en Viena el 30 de marzo del año 1909. Sus padres, el doctor Karl B. Gombrich y Leonie Gombrich, le proporcionaron una vida acomodada que le permitió expandir su intelecto; su padre era un abogado con una amplia cultura, y su madre era profesora de piano, muy aficionada a la música y a las artes decorativas. En este ambiente no resulta raro pensar que Gombrich estuviera desde pequeño relacionado con el arte y la cultura; además, el hecho de nacer en Viena durante esta época de esplendor, junto a los intereses de su familia, promoverá la relación que Gombrich mantendrá con museos, salas de música, la arquitectura barroca que le rodea, etc. Este ambiente, más la formación que recibe después, le llevarán a interesarse por el arte más clásico (Lorda, 1991).

Recibió su educación en uno de los colegios más prestigiosos de Viena, el Theresianum, y sus estudios universitarios en la Universidad de esta ciudad, también muy prestigiosa en el ámbito de los estudios culturales, especialmente de la Historia del Arte. Allí se interesa por autores como Winckelmann o teorías como el Expresionismo. En la Universidad de Viena coincidirá con Swobodo, Tietze, Strzygowsky, etc. Entre sus maestros encontramos a Julius von Schlosser, que será su profesor y posteriormente dirigirá su tesis doctoral sobre el Palazzo del Té, de Giulio Romano, por lo que podemos considerar a Gombrich como un discípulo directo de Schlosser. En el año 1933 terminó la tesis doctoral y la publica en dos artículos (Lorda, 1991).

Cuando E.H.Gombrich finalizó sus estudios en la Universidad de Viena, el antisemitismo crecía a pasos agigantados y no era un buen momento para que encontrara trabajo. En esta etapa de su vida participa en ciertos proyectos, siendo en uno de ellos donde conoce a Ernst Kris, con quien mantendrá una estrecha relación de amistad, y trabajarán juntos en un ambicioso propósito que finalmente no pudieron finalizar sobre la caricatura (Lorda, 1991). A través de Kris, Gombrich conseguió un puesto dentro del Instituto Warburg, un lugar donde se sintió muy cómodo en sus investigaciones, ya que la base científica de este instituto es la Historia de la Cultura. Se trasladó a Londres en el año 1936, donde poco antes también había sido trasladado el Instituto Warburg desde Hamburgo en esa "fuga de cerebros" que se produjo debido al ascenso del nazismo. Desde 
el año 1956 al 1959 trabajó en el Instituto Warburg, donde ocupó el notorio puesto de Director, desde el año 1959 hasta su jubilación en 1976, convirtiéndose en uno de los más recordados y representativos directores que haya tenido este Instituto.

Las influencias que recibió Gombrich son diversas. Por un lado, primero debemos nombrar la Escuela de Viena, a la que pertenece, ya que realiza sus estudios universitarios en ese ambiente. La Escuela de Viena es para el estudio de la historiografía del arte del siglo XX, lo que para el siglo $\mathrm{XVI}$ fue Florencia; es en esta ciudad, Viena, donde comenzamos la idea de la Historia del Arte como Historia de la Cultura, sin duda una característica clara en la teoría del arte de Gombrich (Kultermann, 1996).

En relación con el concepto de Historia del Arte como ciencia debemos nombrar a Karl Popper, con quien inició amistad en Londres, una amistad que daría como fruto un intercambio interesante de ideas y el conocimiento de primera mano de las obras de Popper. Influyó en la concepción que nuestro autor tenía sobre la Historia, pues a partir de ese momento Gombrich estuvo más cerca de ver la historia como ciencia que como historia (Lorda, 1991). La principal aportación de Popper fue el problema de la investigación, contribuyendo al sistema de Gombrich con el concepto de "making and matching", es decir, el ensayo y error. Para él, éste método lo encontramos en la Historia del Arte, como método de aprendizaje de los artistas: éstos abandonan aquellas líneas que son un fracaso y continúan con aquellos logros obtenidos.

Por otro lado, hay que hacer referencia a Ernst Kris a quien conoció en Viena cuando terminaba sus estudios con la tesis doctoral. Lo más importante es que a través de Kris, Gombrich entró en contacto con el mundo del psicoanálisis de Freud, que impregnaba el ambiente intelectual del centro de Europa desde principios del siglo XX y al que el propio Kris pertenecía, pues fue su colaborador. La influencia del psicoanálisis la percibimos en la idea que defiende sobre la percepción de una obra de arte: para él es más importante fijar la atención en cómo se reciben los símbolos y no en la intencionalidad con que fueron formulados, pues es el espectador el que, al contemplar la obra, le añade una significación que no viene dada, según sus experiencias.

Su paso por el Instituto Warburg le aporta ciertas influencias, por lo que debemos hablar de dos de las figuras más importantes de este lugar: Aby Warburg y Erwin Panofsky. En cuanto al primero, Gombrich se une a su concepción iconológica, por lo que entiende la Historia del Arte como la disciplina de interpretación de los símbolos que encontramos en el arte. A propósito de Panofsky, Gombrich se posiciona en contra de su método iconológico, pues el método preiconográfico y el iconográfico se confunden en la mente del espectador, ya que para nuestro autor no hay ninguna mente inocente y nuestra percepción siempre está mediada por los conocimientos adquiridos y las experiencias de nuestra vida.

El contexto, el texto, es decir, las fuentes, y el código o estilo, el modo que elige el artista para revelar visualmente su obra, son las herramientas básicas para el estudio del arte. Y, por último, para él los artistas no parten de su conocimiento visual, de la observación, sino de ideas que les resultan familiares, de las que ya son conocedores. Por esto, el arte siempre tiene un gran contenido intelectual y cada imagen, cada expresión, está más o menos adecuada a la cultura y momento al que pertenece, sin que ninguna tenga un significado totalmente verdadero.

Este breve repaso por las ideas de Gombrich nos ayudarán a entender en el siguiente apartado el método de investigación y los temas que el historiador ha tratado en relación con el objetivo de este trabajo: la teoría de la expresión.

\section{La teoría de la expresión artística en Gombrich}

La teoría de la expresión que encontramos dentro del pensamiento teórico de E. H. Gombrich no se puede llegar a comprender del todo si no se tienen en cuenta las ideas sobre lo que el historiador del arte pensaba que era la percepción de dichas expresiones: cómo llegamos a percibirlas y por qué nos afectan y presentamos una reacción ante ellas. Es por eso conveniente, antes de entrar en la teoría de la expresión, que hagamos un repaso por esas ideas sobre percepción que presenta su 
legado teórico.

En su teoría de la percepción encontramos una de las influencias más importantes que se da en el pensamiento de Gombrich: el método del ensayo y el error de Popper. Así, el mundo es un cosmos y los humanos tendemos a organizarlo para poder llegar a comprenderlo, mediante este método del ensayo y el error, que no sólo es aplicable a la ciencia en sí, sino también a cualquier experiencia de la vida que necesite del conocimiento. Una de las primeras teorías que encontramos es que no hay diferencia entre la percepción y el conocimiento, ambas cosas son lo mismo pues se realizan al instante, a la vez: al percibir una acción o una cosa inmediatamente estamos tomando conciencia de ello, estamos conociéndolo, sea lo que sea (Lorda, 1991). Pero esta acción de comprender exige una hipótesis previa; esta es una idea que en seguida captamos cuando estudiamos la obra de Gombrich, pues para él, en cualquier campo, siempre es fundamental la experiencia anterior, el conocimiento previo, la tradición, las convenciones, etc. No hay nada que aparezca porque sí, de la nada, sino que siempre ese "algo" está ahí, hasta que se encuentra (Lorda, 1991). Por lo tanto, cuando nosotros "vemos" lo que hacemos es formular, a partir de nuestra experiencia anterior, una hipótesis previa de qué puede ser, antes de asegurarnos mediante la mirada. Este método nuestro autor lo ha denominado "Asimetría Popperiana" (Lorda, 1991), y se basa en un procedimiento de conocimiento o percepción economizado, ya que asegura que es más fácil llegar a la conclusión de qué es algo mediante el descarte de aquello que no encaja, que por la confirmación de los puntos que se cumplen, que son más fáciles de encontrar.

Aunque este método esté muy basado en el reconocimiento llevado a cabo por nuestros sentidos, y estos a veces fallan, pues se puede crear una ilusión o encontrar aquello que estamos menos acostumbrados a ver, debido a la extensa experiencia de percepción que acumulamos a lo largo de nuestra vida, nuestros sentidos son cada vez más certeros. Así somos capaces inmediatamente de captar las diferencias y aquello que nos resulta extraño, registrando en ese momento lo raro, que nos llama la atención; ese proceso lo hacemos a través de distinciones, de compararlo con lo que ya conocemos y siendo conscientes de las diferencias. A esto Gombrich lo denomina "categorización" (Lorda, 1991): las primeras categorizaciones son llevadas a cabo de manera inconsciente, por eso es tan necesaria la teoría de que todos tenemos ciertas ideas innatas, como defiende Gombrich; así nuestro intelecto lleva a cabo una hipótesis inmediata, que nos es necesaria para ordenar y comprender el mundo que observamos. Tras estas primeras categorizaciones, relacionadas con nuestras respuestas biológicas, el ser humano adulto presenta una complicada red de categorizaciones, y es esta red la que nos lleva de nuevo a esa idea de Gombrich de la necesidad de la experiencia anterior: cuando percibimos intentamos de primeras insertar lo que vemos en alguna de esas clases ya conocidas que están dentro de nuestra red, y esta es la idea básica alrededor de la cual desarrolla la obra Arte e llusión (Gombrich, 1960).

Otro concepto clave es que esta categorización puede ser llevada a cabo gracias al lenguaje, que crea una necesaria forma de comunicación, mediante una serie de símbolos que nos son comunes a una gran mayoría y que hacen que las experiencias sean transmisibles y fácilmente recordadas. El lenguaje y los símbolos son, como nos dice Joaquín Lorda, "una visión del mundo compartida" (Lorda, 1991, p. 229). Sin embargo, el lenguaje tiene una función más elevada que la de expresar el mundo exterior, pues también necesitamos de él para expresar el interior. Para esta complicada y casi imposible tarea, el lenguaje presenta, pese a sus limitaciones, una salida frente a este problema gracias a su flexibilidad: la metáfora (Gombrich, 1963), que es quizás el concepto más importante de la percepción de la expresión para Gombrich. El funcionamiento de la metáfora se basa en que liga aquello que estamos percibiendo o que queremos expresar con una categoría de nuestra experiencia anterior. Además, Gombrich nos habla de las metáforas fisonómicas o patéticas, que son aquellas que tendemos a hacer mediante la relación entre un sentimiento y un fenómeno exterior, como cuando, por ejemplo, hablamos de un día triste cuando está lluvioso y nublado (Gombrich, 1960). Por otro lado, hay que hablar de la sinestesia, a la que Gombrich hace referencia en su artículo "De la representación a la expresión" (1960); la sinestesia nos demuestra la importancia vital que tiene para nuestra expresión la metáfora, pues no podemos hablar de cómo 
nos afecta un color sin recurrir a ella. Así pues, la metáfora sinestésica es aquella que permite expresar nuestras ideas interiores relacionando éstas con alguna sensación o experiencia del mundo exterior, por ejemplo, usamos una metáfora sinestésica cuando hablamos de que el color azul es "frío". Además, no debemos atender sólo a los parecidos entre elementos, sino a unos valores que encontramos en una escala, para lo que Gombrich utiliza el ejemplo de "ping" y "pong": si hablamos de un elefante y un ratón, todos sabemos a cuál le asignaríamos "ping" y a cuál "pong" (1960, pp. 314-315).

Como rasgo típico de la teoría de Gombrich, encontramos también en estas ideas de la percepción la presencia de la cultura. Estas metáforas no sólo son relaciones entre un sentimiento interior y una sensación o elemento exterior que nosotros asociamos, sino que también provienen de las personas que nos rodean y que comparten ciertos valores por vivir en una misma cultura. Así, todo aquel que pase a ser miembro de una cultura también se tendrá que incorporar a ese lenguaje común para poder compartir esas referencias y comunicarse (Lorda, 1991) y además, puede también crear otras nuevas que se pasarán con el tiempo a ser parte de su cultura. El peligro de la metáfora es que puede ser convertida en mito, es decir, que llega un punto en el que se convierte en una convención y hemos llegado a creer que esas asociaciones creadas con el paso de los años son naturales. Nos hemos acostumbrado tanto que no seríamos capaces de percibir o reconocer ciertos elementos o acciones si no existieran.

Entrando ya en un concepto más artístico, para Gombrich la obra de arte es una metáfora, no sólo porque expresa un sentimiento o una situación, sino porque ayuda a que ésta consiga un lugar en el mundo, un nombre, una sintetización, y a través de ella somos capaces de percibir matices y sensaciones que seríamos incapaces de expresar con palabras. Otra de las ventajas de la obra de arte como metáfora es que se percibe "a un tiempo" (Lorda, 1991), es decir, podemos percibir condensadas en una sola obra muchas sensaciones y sentimientos que se representan en ella, y lo hacemos en el mismo instante en que la vemos, todo lo percibimos al instante.

Para finalizar con este apartado se podría concluir que, a partir de esta idea de metáfora y su aplicación al arte, para Gombrich la Historia del Arte es una búsqueda continua de metáforas que consigan expresar o remover este o aquel sentimiento en los espectadores. Son, sobre todo, las obras figurativas las que despiertan en nosotros lo que Gombrich denomina "sentido de significado", es decir, activan nuestra mente para intentar adivinar qué son y cómo se han realizado. Pero también hay obras no representacionales y esto Gombrich no lo deja al margen, especialmente por la predilección que siente hacia el arte de la música, que ilustra lo que nuestro autor quiere decir comparando la obra de arte con la metáfora mejor que ninguna otra, pues la música, sin figuración, es capaz de transmitirnos frío, miedo, tensión, alegría, e incluso podemos con ella escuchar el viento o las tropas de un batallón. Como conclusión, podemos comprender mucho mejor una emoción o una sensación a través de una imagen o un sonido, que a través de una descripción realizada con un montón de palabras que están limitadas para representarlo.

La cuestión de la expresión es uno de los temas que más preocupación ha despertado en el pensamiento de Gombrich y, sin embargo, no es algo que quede claro a primera vista. Gombrich siente un gran interés por la expresión debido, entre otras cosas, a la enorme admiración que tiene hacia la música, con la capacidad que ésta presenta para mostrar sensaciones y sentimientos sin necesidad de una imagen visual, sin una referencia, aunque es cierto que los sonidos despiertan ciertas respuestas cuando llegan a nuestros oídos. Más que confirmar ciertas teorías relacionadas con la expresión, lo que Gombrich realiza en sus estudios es la tarea de desmentir ciertas ideas para eliminar aquellas que, según él, no se ajustan del todo, y quedarse con las que nos den una idea más cercana a la verdad. Así, nuestro autor va a desmentir ideas que han estancado la crítica y la teoría del arte en convenciones no del todo ciertas según él, como que una obra de arte expresa el estado de ánimo de un artista o que dicha obra sea la expresión de una época. Por tanto, vamos a comenzar hablando de dos teorías que para Gombrich no son del todo ciertas: la "teoría grafológica o fisonómica" y la "teoría de la resonancia" (Lorda, 1991).

La primera teoría es la grafológica, según la cual la obra de arte es la expresión del carácter 
del artista que la realiza, pues en ella podemos intuir esos rasgos de su personalidad. La teoría de la resonancia (Gombrich, 1963) se basa en la creencia en que una obra de arte es la expresión de cierta emoción interior del artista, haciendo de este modo comunicables sus sentimientos, expresándolos, a través de la obra que ha realizado. A partir de la observación de esa obra el espectador "resuena" o vibra con los sentimientos que el artista ha plasmado en ella. Estos son dos puntos muy importantes en la teoría de la expresión, y ambos tienen que ver con la capacidad del arte para expresar. Por otro lado, podemos entender la obra del artista dentro del contexto cultural o civilización en el que se ha dado, pero para Gombrich, esto no puede suceder al contrario, pues el artista es totalmente individual, aunque dentro de su cultura, y, como dice en su artículo "El psicoanálisis y la Historia del Arte" (1963), no se puede resucitar a aquellos maestros para analizar qué razones les llevaron a crear esa obra.

En cuanto a la teoría que sostiene que a través de la obra de arte podemos conocer la personalidad del artista, Gombrich nos habla del problema que supone las conclusiones inmediatas. Llegamos a ellas a través de la facilidad con que leemos ciertas expresiones (Gombrich, 1963), suponiendo con ello el carácter de la persona representada o, en este caso, que representa, componiendo de esta manera un juicio; y es ahora cuando el dicho popular "no dejarse engañar por las apariencias" cobra su mayor sentido para Gombrich. Como he dicho antes, en su artículo "El psicoanálisis y la Historia del Arte" (1963), vemos cómo Gombrich no cree que podamos saber qué pretendía exactamente expresar el artista, puesto que ya no podemos conocerle y, por tanto, no podemos tampoco dar una respuesta científica y objetiva. En cuanto al segundo aspecto, el de la teoría de la resonancia, debemos hablar de la Teoría de la Información (Gombrich, 1963), que se basa en que se necesita un código anterior al mensaje, que conozca también el receptor, para que se pueda dar la comunicación; con esto resalta las limitaciones que conllevan el medio, es decir, el lenguaje. Es muy necesario que el espectador sea capaz de crear una resonancia con aquello que el artista expresa, y por eso, es necesario que el medio no tenga fallos, pues de esta forma no se podría producir dicha resonancia.

Como vemos, Gombrich nos convence de que es imposible conocer a través de la producción artística los sentimientos o la personalidad de un artista, pero además cabe añadir que no es ese el objetivo del arte, pues no podría existir una historia que se basara en el principio de la expresión. La Historia del Arte se basaría en una montaña de ideas, sentimientos y personalidades sueltas, inconexas, de los artistas, pues se fundaría en cuestiones personales (Gombrich, 1963). Esta manera de verlo dejaría de lado muchos siglos de arte, aquellos momentos en que éste era anónimo y las obras eran realizadas en obradores. Por último, estas ideas de la expresión del artista dejan de lado una de las ideas que Gombrich defiende con mayor vehemencia: el estilo, la conexión con otros períodos artísticos, la asimilación de las novedades, etc. En esta línea, Gombrich nos habla de la necesidad de una teoría que supere estas limitaciones, pero que sea al mismo tiempo capaz de aceptar el arte como expresión. Ésta se va a argumentar a partir de la creación que él denomina “feedback"(Gombrich, 1980), y que está formada por las convenciones, que tan importantes son para Gombrich.

\subsection{Las cuatro teorías de la expresión artística}

En el artículo titulado "Cuatro teorías sobre la expresión artística" (Gombrich, 1980), Gombrich nos presenta una posible evolución general de las teorías de la expresión artística desde la época clásica al Romanticismo, añadiendo además una teoría que vendría a unir las anteriores en una sola, creando un punto intermedio que para él se aproxima más a la realidad de la expresión en el arte. Estas teorías se basan en que en cada una de esas épocas predomina un elemento: la señal, el signo y el síntoma.

El lenguaje, dentro de la expresión, tiene tres funciones fundamentales: la función síntoma, cuando un sujeto expresa que una emoción le ha afectado, es decir, cuando muestra los síntomas que puede crear una emoción sobre una persona; la función señal, que se basa en la reacción 
que despierta la acción de un sujeto en otro, una señal de una persona y la respuesta hacia ésta del receptor, y la función símbolo, que alude específicamente a la emoción; por describirlo de una manera clara, aunque demasiado resumida quizás, es el símbolo de una emoción. Aéstas, Gombrich añade la teoría centrípeta (1980), de la que hablaré más adelante, y cada una de estas funciones se da en diferentes fases de la Historia del Arte. Así pues, la función síntoma alude al sujeto individual, la señal a los compañeros de éste y la función símbolo a la emoción en sí, como nos explica Lorda (1991, p. 378). También este autor nos llama la atención sobre la influencia de Karl Bühler, que encontramos en la creación de esta teoría, pues estas funciones del lenguaje son las que Bühler anuncia en su teoría del lenguaje (1918).

Acontinuación, veremos estas funciones dentro del momento en que se dieron. Para Gombrich, a lo largo de toda la Historia del Arte se han realizado búsquedas de elementos que crearan una respuesta en el espectador y destaca la capacidad del medio y la necesidad de éste para crear dichas emociones (Lorda, 1991). Uno de los mejores medios es la retórica (Gombrich, 1980), que tuvo una importancia vital en la Antigüedad clásica, a la que pertenece la función señal. Esta función nace ya en tiempos primitivos, cuando se descubre el poder que el arte tiene para influir sobre el ser humano, por lo que Gombrich va a denominarla también función "médico-mágica" (Gombrich, 1980), pues los pueblos primitivos creen que las imágenes poseen un poder elevado. Durante la etapa de la función señal, que perdura hasta el Renacimiento, lo más importante es que no importa que el artista haya sentido la emoción que representa, sino el poder que dicha representación consigue sobre los demás. Como decíamos antes, la función señal se basa en la respuesta que consigue la acción (en este caso la realización de una obra) sobre una segunda persona. La función simbólica comienza a finales del siglo XVI y perdura hasta el XVIII, y podemos decir que está estrechamente relacionada con la teoría de Leonardo da Vinci (1680). Lo más importante de este período es la capacidad del artista, la maestría, para representar dichas emociones de la forma más realista posible, por ello, Gombrich la denomina "función dramática"(Gombrich, 1980). Si vemos pintura de estos momentos, podemos observar cómo las figuras se relacionan entre sí a través de gestos que simbolizan o son metáforas de acciones, emociones, etc.; el mejor ejemplo para esto es La Última Cena, precisamente de Leonardo da Vinci. Y por último, la función síntoma (Gombrich, 1980), que pertenece al siglo XVIII, pero sobre todo a la teoría artística del Romanticismo, momento en que el artista se convierte en el centro del mundo del arte. Se busca la expresión más sincera, y lo que se tiene en cuenta es la expresión de las emociones interiores del artista. Ahora, la retórica queda obsoleta y se tiene por insincera. Lo importante es que la obra de arte se considera el lugar donde se reflejan los síntomas de los sentimientos más profundos del artista, sin tener en cuenta el medio, el lenguaje. Se considerará un fraude toda aquella obra de arte que hable de un sentimiento y haya sido creada por el artista sin sentirlo, de manera que un pintor no debe crear una pintura de amor sin sentir amor por una persona en ese momento.

Pero Gombrich no está de acuerdo con la relación que establecen estas teorías entre el espectador y el artista, por lo que él mismo da su propia opinión sobre el tema de la expresión. Esta teoría se denomina "centrípeta" y surge como oposición a la teoría expresionista "centrífuga" (Lorda, 1991, p. 381). En contra de esto, usa esta teoría centrípeta según la cual el artista debe basarse en los códigos, en el medio, que ya está establecido, que existe, y que le dará la solución a su obra, una vez que los descubra. Además, el artista sólo puede transmitir los sentimientos que son comunicables a través de esos códigos, por lo que, para nuestro autor, no se trata de la expresión total de dichas emociones, sino de aquellas que puede encontrar en el lenguaje que le viene dado (Gombrich, 1980). Enlazamos con la teoría de la función simbólica, pues aquí ofrece al artista un arsenal de fórmulas que puede adquirir de la tradición. Pero el hecho de que el artista utilice estas fórmulas no le quita mérito, pues para él, el hombre es un ser articulado que necesita de esos medios exteriores para poder comunicarse, de esas fórmulas que se encuentran en la tradición, que el artista puede adaptar, mejorar, etc., pero de las que no puede prescindir porque las necesita para autoconstruirse como persona y para poder relacionarse con su entorno. Según él, las fórmulas son las que nos ayudan a comprender aquello que sentimos dándonos una definición de ello, de manera 
que nosotros podamos reconocerlo y expresarlo. Así, como nos dice Lorda, "Gombrich afirma que la fórmula crea la expresión" (1991, p. 382). Por último, añadir que el nombre que Gombrich le da es "teoría feedback" (Gombrich, 1980), pues nos habla de una continua interacción entre la fórmula, el sentimiento y viceversa, tema que estudiaremos a continuación.

a. Las fórmulas, las disposiciones biológicas y la tradición como instrumentos de la expresión. El papel del artista.

En el punto anterior decíamos que las fórmulas eran el vehículo fundamental para la expresión hacia el exterior de un sentimiento y, por tanto, no sólo funcionan para la persona que expresa, sino que también tienen una función con respecto a quien la recibe, es decir, las fórmulas también son claves a la hora de suscitar emociones en los demás. No debemos hacer una distinción entre la fórmula y la expresión, ni mucho menos hacer una distinción en la que la fórmula sea infravalorada ya que, de hecho, ambas están en continua interacción (Lorda, 1991). Son, enlazando con las "Cuatro teorías de la expresión artística" (Gombrich, 1980), la relación existente entre el símbolo y el síntoma: al ser el primero el que suscita el segundo, su relación es constante y necesaria.

En este punto debemos hablar de la teoría James-Lange (Lange, 1922 y James, 1884), que se da dentro del estudio de la psicología. El síntoma aparece de manera automática como reacción siempre que nos invade una emoción, un sentimiento o un estado de ánimo. Aunque, como nos dice esta teoría, no siempre debe darse una acción para que aparezca un síntoma, pues estos pueden aparecen a propósito, por capricho del individuo, de manera que podemos fruncir el ceño o mostrar una sonrisa sin necesidad de sentir enfado o alegría justo en ese mismo instante. Pero, por otra parte, también el hecho de imitar un estado o emoción puede llegar a hacernos sentirla de verdad, es decir, si un individuo frunce el ceño por capricho, puede llegar a suscitarle un sentimiento de enfado real. Sabemos qué debemos hacer para llegar a enfadarnos, para alegrarnos, etc., y el mejor ejemplo de ello se ve en el usado por Lorda: un niño pequeño sabe qué hacer para llorar continuamente, dejándose llevar por ese sentimiento de desesperación, hasta conseguir lo que desea (1991, p. 384). Gombrich hace referencia a las ideas de esta teoría en algunos de sus escritos, como en el caso de "Cuatro teorías sobre la expresión artística" (1980). Sin embargo, la teoría de Gombrich sobre la expresión no está totalmente ligada a la James- Lange, pues no todas las fórmulas funcionan siempre, ya que también dependen de las culturas o las tradiciones, de manera que es muy diferente la forma de reaccionar de un hombre latino de la de alguien perteneciente al norte de Europa. Por esto, debemos pasar al repaso de las siguientes ideas de este punto del trabajo: la acción de las disposiciones biológicas y las tradiciones culturales. Gombrich habla de la importancia de éstas en un artículo que formó parte de una conferencia del año 1985, que recibe el título de "They were all humans beings- So much is plain: Reflections on cultural relativism in the humanities", de las que podemos sacar en claro tres ideas: no se puede pretender recoger todo el sentimiento de una época a través del arte de ésta, ya que hay veces que el sentimiento no consigue ser expresado mediante los medios existentes de forma correcta. Por otro lado, Gombrich afirma que las tradiciones artísticas se han creado a partir de las reacciones humanas más básicas y automáticas, utilizando éstas para sublimarlas, transformarlas, etc., es decir, estas reacciones básicas se toman como punto de partida. Y, por último, esas reacciones que se deben a nuestras disposiciones biológicas, no son puras, sino que se pueden ver mermadas o mejoradas según el contexto social o cultural en el que las encontramos.

Las disposiciones biológicas que están en el ser humano de forma innata son las que consiguen que, como en el ejemplo anterior, aunque la reacción de alegría de un latino ante una buena noticia y la de un individuo del norte de Europa sean muy diferentes, ambos puedan comprender que esa reacción es positiva y alegre. Este tema va a dar como fruto el artículo "Metáforas de valor en el arte", en el que analiza "(...) cómo, en el pasado histórico, se han manejado los colores y los contornos para provocar una impresión (...)" (Gombrich, 1963, p. 15). De esta manera, siempre se han usado en el arte ciertos materiales, colores, formas, brillos, etc., que nos resultan más o menos agradables, que expresan esto o aquello, y que nos afectan así de manera natural, es decir, nos resulta agradable naturalmente. Esto es precisamente lo que le otorga al arte la categoría de 
metáfora, pues al trasladar nuestras reacciones biológicas a las convenciones artísticas consiguen que establezcamos relaciones entre objetos, acciones, etc., con cualidades determinadas, como metáforas sinestésicas (Gombrich, 1963). Teniendo en cuenta esta reflexión se comprende el poder del arte, que pone nuestras reacciones básicas a disposición de su beneficio. Hay que añadir que una de las metáforas visuales más importantes se basa en la renuncia (Gombrich, 1984), pues no sólo el brillo y el color nos llama la atención, sino que además en toda civilización existe una relación de tensión entre la pureza y lo decorado, por lo que también lo sencillo nos resulta agradable, e incluso lo asociamos a lo culto y refinado; un ejemplo de ello es la arquitectura cisterciense.

Es a causa de estas relaciones de tensión y por la capacidad de las culturas para acceder a ciertos logros artísticos, por lo que Gombrich nos dice que hay que tener muy en cuenta estas reacciones de satisfacción y renuncia, basadas en nuestras disposiciones biológicas, ya que sobre ellas se configuran las convenciones artísticas según cada civilización; la tradición se convierte en un instrumento para la expresión. El artista encuentra una amplia colección de elementos y modos que puede utilizar en su obra porque, debido al paso de los años, se han convertido en convenciones artísticas que el público reconoce, y este es el concepto de estilo. El estilo, en resumen, está compuesto por una serie de recursos que enganchan con nuestras disposiciones biológicas y éstos hay primero que descubrirlos para poder utilizarlos. El arte, por ello, se basa en ir descubriendo esas llaves que consiguen abrir la cerradura del interior del espectador, y que no siempre está entre la tradición, ni mucho menos la encontramos en estudios psicológicos.

A continuación, vamos a hablar de algunas de las ideas principales del artículo de Gombrich clave para entender cómo el arte consigue representar las emociones y transmitirlas, si se asienta en la imagen visual fija. Gombrich comienza el artículo con la frase popular "sólo le falta hablar" (1982, p. 75), haciendo referencia a una obra de arte, pues es exactamente eso lo que consigue la obra, transmitirnos una realidad. Sin embargo, el arte presenta importantes carencias para la expresión de una realidad, como el movimiento físico e incluso el de las emociones, como puede ser el enrojecimiento de las mejillas. Aun así, consigue crear una representación, un equivalente, que quizás no guarda mucho "parecido", pero sí realizan la misma función, ya sea un sentimiento o un caballo de juguete (Gombrich, 1963). Y lo consigue mediante un proceso que Gombrich denomina "de tanteo", según el cual el artista no comienza observando la naturaleza e intentando representarla de manera lo más cercana posible a ella, sino creando unos "modelos mínimos" a partir de convenciones sobre representación que el artista va descubriendo o encuentra en la tradición. Éstos modelos se van ajustando hasta que consiguen crear en el espectador una impresión: “(...) los recursos de que carece el arte se han de compensar por otros medios hasta que la imagen satisfaga los requisitos que se le imponen" (Gombrich, 1982, p. 75). Así, para nuestro autor, la Historia del Arte no es un mero ejercicio de aproximación a una fórmula, como hemos podido vislumbrar en otros puntos de este trabajo, sino que cada época se ha centrado en un aspecto diferente de los compensatorios, de los que carece el arte, y por eso aparecen los estilos, a los que Gombrich hace constante referencia (1982).

Según el historiador del arte, la imagen visual fija debe tener al menos dos aspectos para que desarrolle su función expresiva: los movimientos deben estar formados a partir de configuraciones que sean rápidas y fáciles de entender, así como es necesario que se muestren en un contexto también claro y entendible, para poder ser interpretado. "Hablando sobre las reacciones positivas o negativas ante un objeto externo, Engel observa que ambas están marcadas por una "posición oblicua del cuerpo" (1982, p. 77). Esto conlleva que para la representación, como ya hemos dicho antes, del movimiento expresivo, necesitemos una serie de configuraciones. Ello comporta un problema, ya que en algunos casos dichas configuraciones no son del todo comprensibles, como podría pasar en un combate con movimientos violentos entre varios personajes. Por eso, en las representaciones grupales, hubo que recurrir al "simbolismo social" (Gombrich, 1982, p. 79), en el que se usa la perspectiva jerárquica, atributos, y toda una serie de gestos y posturas simbólicas, que la tradición ha ido acuñando en las diferentes tradiciones (Gombrich, 1982). Por último, nos dice Gombrich que es muy importante la claridad en el contexto que rodea la representación de una 
emoción, ya que la reacción a una expresión suele darse mediante una cadena de movimientos sucesivos, ya sea echarse las manos a la cabeza o fruncir el ceño, y eso es algo que el arte no puede darnos. Por ello, es muy importante que las configuraciones establecidas para representar alguna de esas expresiones vengan acompañadas de un contexto que nos de pistas para la interpretación de la escena (Gombrich, 1982).

Con la llegada del cristianismo, pasamos a un estilo que denomina "pictográfico" (Gombrich, 1982, p. 84), basado en una serie de configuraciones conceptuales que representan el "qué", pero no el "cómo", dándose una nueva normalización de los gestos simbólicos. Ahora, la necesidad se centra en la representación del "qué", y en mensajes altamente comprensibles e inequívocos a primera vista, como la representación de un Cristo Pantocrátor, ya que el arte de estos momentos sirve para educar al pueblo cristiano analfabeto. Así, podemos concluir que existe un arte que se basa en la representación pictográfica de ciertas escenas, en las que ya no interesa la interacción entre figuras, sino una expresión inmediata, un instante a partir del cual entendemos el resto de la historia. Un recurso también importante para el arte, especialmente si es pictográfico y necesita muchas pistas para su interpretación correcta, es el coro, es decir, la aparición de un público, una serie de personajes totalmente secundarios que está presente en la escena que se representa y también presenta una expresión o reacción hacia lo que está presenciando y nos ayuda a saber qué debemos sentir o cómo debemos reaccionar los espectadores, que somos también el público de dicha escena (Gombrich, 1982).

Otro concepto importante se dio, sobre todo, a partir del arte del Renacimiento, tema en el que Gombrich es un erudito. En el Renacimiento se supera el arte pictográfico y se realizan obras en las que se añade más información a la escena, más datos. Por esto, aparece un concepto de importancia vital: el decoro, es decir, la adecuación del tono de la expresión de la representación, que debe encontrar un punto intermedio entre los movimientos de la mente del personaje y los que se muestran al exterior (Gombrich, 1982). Sin embargo, el decoro no presenta unas leyes universales, pues depende del énfasis que esté bien visto representar en un estilo de una época determinada, del carácter más o menos temperamental, o incluso del propio carácter de las figuras que se representan, por lo que las figuras de Leonardo "gesticulan como locas" (Gombrich, 1982, p. 89) si las comparamos por ejemplo con las de Ghirlandaio. De nuevo, esta idea del decoro cambia cuando llegamos a la época de la Contrarreforma y el Barroco, en la que se intentaban representar de manera categórica estados extremos, como el éxtasis. Por último, nos señala que el arte septentrional, donde el carácter es calmado y quizás "frío" en comparación con el latino, se basa en la expresión a partir del rostro, mediante gestos tranquilos que nos acompañan a la meditación y que, al no aparecer ningún movimiento excesivamente teatral, no hay cabida a los errores en la interpretación (1982, pp. 93 a 95). Finalmente, el siglo XX queda al margen de las ideas que acabamos de ver enunciadas, ya que éstas se basan en la expresión figurativa, mientras que el arte contemporáneo acaba con todo esto, mediante la ruptura con las convenciones, llegando incluso a la abstracción. Sin embargo, es concebida a veces como la máxima expresión de los sentimientos más profundos del artista. Lo que está claro, es que la relación entre el arte y la expresión de los sentimientos van ligadas desde los comienzos de la Historia del Arte hasta nuestros días, donde parece que ésta ha terminado.

Hemos visto a lo largo del desarrollo de este trabajo que Gombrich ve la Historia del Arte como una historia de los estilos, una historia de los descubrimientos de fórmulas...pero la verdadera visión que tiene de la Historia del Arte es como Historia de los Artistas, incluso dedicándole un capítulo en su libro La Historia del Arte (1950). Así, aparecen los grandes maestros, los grandes artistas, que son aquellos que realmente han creado la Historia del Arte, usando de manera magistral las fórmulas. El artista es quien tiene la responsabilidad y, al mismo tiempo, la virtud de saber qué hacer con las reacciones biológicas y las tradiciones que les vienen dadas y jugar con ellas de manera correcta, consiguiendo crear en el espectador una reacción, una vibración. A la vez, con esos descubrimientos, también enriquecen su tradición artística, bebiendo y, al mismo tiempo, contribuyendo a ella (Lorda, 1991). Volviendo a la influencia de Popper y al método del "ensayo y el 
error" tan característico en Gombrich, los artistas prueban y prueban hasta que consiguen encontrar esa llave que permite abrir la mente del espectador (Gombrich, 1960), por lo que donde reside la maestría del artista es en la creación de metáforas.

Pero no debemos dejar a un lado el sentimiento del artista, pues, en la combinación pertinente de su medio para crear las fórmulas, también interviene el mundo interior del artista, que puede ser considerado como el motor que pone en funcionamiento el proceso de búsqueda de una fórmula dentro de las tradiciones (Gombrich, 1971). Según estas ideas vistas, podemos concluir con que la verdadera tarea e importancia del artista es la "autenticación". Las elecciones del artista han sido tomadas porque han conseguido tener efecto en él, por lo que también da la seguridad de que lo tendrá en el espectador, y ambos resuenan ante la obra de arte. El hecho de que el artista haya elegido esas configuraciones, valida a éstas para que resuenen en nosotros, porque ya lo han hecho en él; así, el artista se convierte en su primer espectador (Gombrich, 1984).

Como hemos visto, el artista aporta su sensibilidad y no basa sus elecciones en sus propios intereses o sentimientos interiores, al menos no tiene por qué ser así siempre, sino que las elige por ser capaces de crear un efecto determinado. $Y$ el artista que pasará a la historia es aquel que encuentra la llave, la fórmula, que no sólo le hace vibrar a él, sino que consigue también hacernos vibrar a nosotros. $\mathrm{Y}$ así finalizamos este punto sobre la expresión en el pensamiento de $\mathrm{E}$. $\mathrm{H}$. Gombrich, tras este repaso por los principales elementos que, según el historiador, hacen posible que el arte refleje la expresión pese a sus limitaciones.

\section{Reflexiones finales}

En este trabajo hemos hecho un repaso por las ideas principales de Gombrich, como uno de los más influyentes historiadores del arte de todos los tiempos, sobre la expresión en el arte, siempre teniendo en cuenta su formación, influencias e ideas principales. Como conclusión, para Gombrich la expresión artística está basada en la metáfora, el medio, pues es a partir de la percepción de ésta como podemos llegar a comunicarnos y comprender lo representado. La metáfora se forma a partir de las convenciones, del uso de una serie de símbolos que se convierten en parte de la tradición de una civilización, común a todos. Y esta importancia que otorga a la Historia de la Cultura y las tradiciones y convenciones de cada pueblo, viene por la influencia de la Escuela de Viena, en la que el historiador del arte obtuvo su formación. Por otro lado, el método que utiliza para exponer su teoría de la expresión se basa en la ya vista "Asimetría Popperiana", según la cual es un método más económico de investigación descartar aquellas teorías que no son ciertas. Por ello, va a desechar para comenzar la teoría de la resonancia y la teoría grafológica, que para él no son ciertas porque no se pueden crear universales a través de una obra de arte, ya que no podemos conocer la personalidad de un artista o toda una época a partir de una de ellas.

Las Cuatro Teorías de la Expresión son la base más firme sobre la que se sustenta la teoría de la expresión de Gombrich y, además, constituyen quizá el artículo que de manera más clara se dedica a la expresión artística dentro de su obra. Con ella podemos comprender que durante la etapa clásica necesitábamos de la función señal, donde lo importante es el poder que la imagen realiza sobre los demás, en mi opinión, pudiéndolo relacionar con la teoría hegeliana del Espíritu, de la evolución de la civilización. La función que predomina del Renacimiento al siglo XVIII es la función símbolo, donde lo importante son las configuraciones de las obras y, por esto, es el gran momento de los tratados artísticos, en los que se explica cómo se deben representar escenas o figuras. Por último, llegamos al Romanticismo, donde el artista y su sentimiento se convierten en los protagonistas del arte, mediante la función "síntoma". Pero Gombrich nos presenta la cuarta, un punto intermedio entre las anteriores, llamada "centrípeta", según la cual el artista tiene la capacidad de hacer resonar al público mediante la correcta elección de ciertas configuraciones que adquiere de la tradición, de la cual se alimenta y, al mismo tiempo, contribuye a renovar. Por esto, para nuestro autor, lo crucial es la capacidad y sensibilidad que presenta a la hora de encontrar ciertos matices que le hacen vibrar a él, para después plasmarlo en una obra que nos hace vibrar a nosotros, a su 
público. El artista es un seguro de calidad. Y, para finalizar con estas conclusiones, hay que señalar que esas fórmulas que el artista escoge son capaces de hacernos vibrar porque presentamos una serie de reacciones biológicas automáticas hacia ciertos estímulos, como la luz, el brillo o la sencillez o pureza; valores con los que, uniéndolos a la tradición (con los estilos o los gestos ritualizados), el artista juega para hacernos resonar con su obra.

La teoría de la expresión de Gombrich presenta puntos que responden a una muy buena lógica, muy argumentados, pero quizás actualmente no tendrían cabida entre el arte contemporáneo, pues no encontraría sustentación, ya que hemos podido comprender que para Gombrich la expresión se representa mediante la figuración, ya que ésta se basa en gestos, posturas, etc., y el arte en nuestros días no se ha apoyado siempre en el arte figurativo. La importancia que Gombrich le proporciona a la tradición y las convenciones, es algo que hoy parece para muchos críticos y artistas una atadura o límite impuesto al arte, y piensan que éste debe liberarse mediante el famoso concepto de "autonomía del arte". Sin embargo, creo que las convenciones son usadas con una gran lógica, ya que se puede pensar que los artistas necesitan de una base en la que apoyarse, bajo la creencia de que no existe la mente inocente sino que todas están mediadas por las experiencias anteriores.

Este trabajo ha realizado un repaso por la teoría de la expresión de Gombrich, cuya repercusión quizá actualmente no haga justicia a la importancia que ésta presenta, debido a su relación con las convenciones y la tradición, pero que es de una gran originalidad y se encuentra perfectamente argumentada, pudiendo servirnos para formar una idea personal a partir de ella, y entender de manera lógica por qué el arte puede llegar a transmitir una emoción, un sentimiento, en el momento en que estamos disfrutando de su visualización.

\section{Bibliografía}

Bühler, K. (1985). Teoría del lenguaje. Madrid: Alianza.

Danto, A. (1964). El mundo del arte. Journal of Philosophy, 61, 19, 571-584.

Gombrich, E. H. (1971). Freud y la psicología del arte. Estilo, forma y estructura a la luz del psicoanálisis (pp. 9-43). Barcelona: Barral Editores.

Gombrich, E. H. (1980). Four theories of Artistic Expression. Architectural Association Quaterly, 12, 14-19.

Gombrich, E. H. (1984). Tributos: Versión Cultural de Nuestras Tradiciones, Madrid: Fondo de Cultura Económica de España.

Gombrich, E. H. (1985). They were all humans being- So much is plain: Reflections on cultural relativism in the humanities. Critical Inquiry, 13, 4, 686-699.

Gombrich, E. H. (1987). La imagen y el ojo. Madrid: Alianza.

Gombrich, E. H. (1998). Meditaciones sobre un caballo de juguete. Madrid: Debate.

Gombrich, E. H. (2003). Arte e llusión. Estudios sobre la psicología de la representación pictórica. Madrid: Debate.

Gombrich, E. H. (2006). La Historia del Arte. Barcelona: Debate.

James, W. (1844). What is an emotion? Mind, 9, 188-205.

Kultermann, U. (1996). La Escuela Vienesa de Historia del Arte. La Historia de la Historia del Arte (pp. 213-233). Madrid: Akal.

Lange, C. G. (1922). The emotions. Baltimore: Williams \& Wilkins Company (ed. original de 1885).

Lorda, J. (1991). Gombrich: una teoría del arte. Barcelona: Ediciones Internacionales Universitarias.

Woodfield, R. (ed.) (1996). Gombrich Essential. Madrid: Debate. 



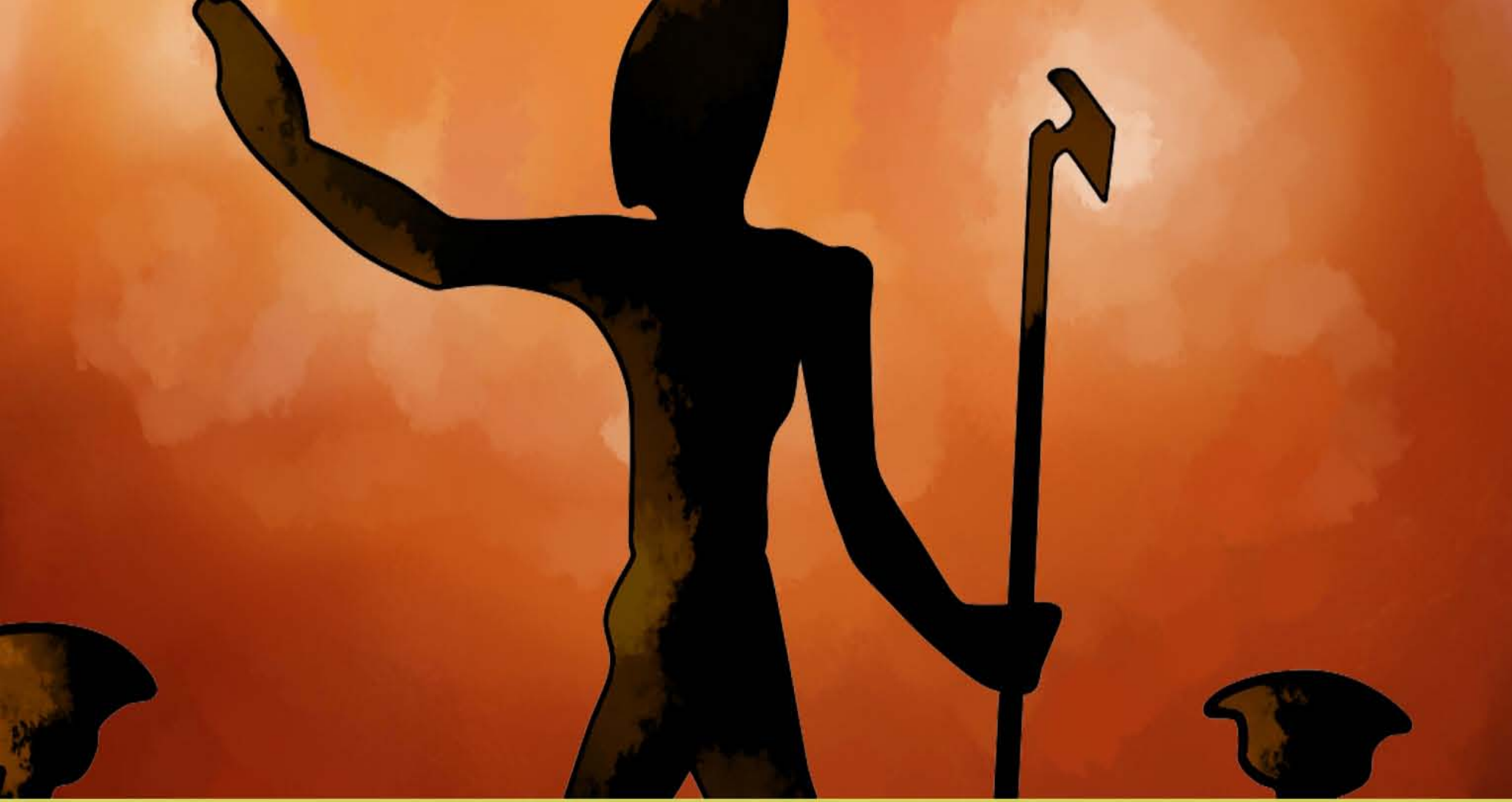

